\title{
Performa Motor Induksi Satu Phasa Sebagai Penggerak Mesin Pengering
}

\author{
Erliza Yuniarti ${ }^{1}$, Sofiah $^{2}$, Aldo Saputra ${ }^{3}$, Adi Pani ${ }^{4}$, Mukhlis Muhammad ${ }^{5}$ \\ 1,2,3,4,5Electrical Engineerring, Faculty of Engineering, Universitas Muhammadiyah Palembang, \\ Indonesia \\ Email :1erlizay@yahoo.com, 2sofikeran12@gmail.com, ${ }^{3}$ aldosaputra58690@gmail.com, \\ 4adipani91@gmail.coms,5mukhlismuhammad56@gmail.com
}

\begin{abstract}
Utilization of an induction motor as a driving force for an oil drying machine because of its strong construction and easy maintenance. The dryer is designed to use a tube made of aluminum with an iron frame equipped with a dimmer as a voltage regulator and a timer for setting the drying time. The engine performance test was carried out with a voltage variation of 80-100 Volts with a time of 30-240 seconds with a constant load weight. Based on the research, the performance of the dryer was obtained, at a voltage of 90-100 Volts, the engine speed was stable at $2500 \mathrm{rpm}$ in a drying time of $90-120$ seconds. The decrease in load in the drying process can increase the rotation of the motor, otherwise the motor torque will be smaller with the increase in motor rotation and the length of the drying process.
\end{abstract}

Keywords: induction motor, dimmer, performance

\section{PENDAHULUAN}

Motor induksi bekerja berdasarkan besarnya arus pada rotor yang teriduksi sebagai akibat adanya perbedaan relatif antara putaran stator dengan medan putar, dan medan putar akan mengiduksikan tegangan ke rotor sehingga menimbulkan medan magnet [1]. Motor induksi merupakan salah satu jenis motor arus bolak balik yang banyak dipergunakan di industri, bahkan mencapai 30\% dari total keseluruhan energi [2]. Pemilihan pemakaian motor induksi dikarenakan keunggulan jenis motor ini diantaranya adalah konstruksi yag sederhana, kuat, dan mudah untuk dipengoperasikan [3]. Mendapatkan torsi yang baik dari suatu motor induksi adalah dengan merubah parameter desain yaitu meliputi alur stator dan alur motor, yang menghasilkan torsi yang tinggi [4]. Pada aplikasinya motor induksi banyak dimanfaatkan sebagai penggerak belt conveyer, blower, pengering, pada peralatan elektronik untuk rumah tangga seperti kipas angin dan mesin cuci.

Tujuan penelitian adalah mengetahui performa motor induksi satu phasa sebagai motor penggerak pengering dengan pengaturan kecepatan motor . Mesin pengering dimanfaatkan untuk meniriskan minyak dari produk pangan yang telah digoreng [5], yang diaplikasikan untuk peniris minyak pada makanan khas 
Palembang yaitu usaha kemplang atau kerupuk menggantikan koran atau kertas yang selama ini dipergunakan. Dimensi kemplang-krupuk goreng yang beragam, ringan dan rapuh atau mudah patah, tidak dapat dikeringkan dengan kecepatan putaran yang tinggi dalam waktu lama [6]. Sehingga motor penggerak peniris dirancang dengan setting kecepatan dan lama operasinya dengan menggunakan timer.

Penelitian terdahulu membahas pengaturan kecepatan putar motor telah dilakukan dengan diantaranya adalah menggunakan pengering memiliki timer sebagai pengatur waktu, dengan kecepatan putaran 1076 rpm serta kapasitas filter sebesar $10 \mathrm{~kg}$ memiliki performansi yang baik untuk megurangi kadar minyak pada abon ikan [7] ; mengubah frekuensi dengan memanfaatkan inverter satu fasa dan mengkonversikan sumber tegangan arus bolak balik tiga fasa maupun sumber tegangan bolak balik 1 fasa yang bekerja dengan frekuensi konstan $50 \mathrm{~Hz}$, menjadi sumber tegangan yang frekuensinya dapat diatur antara $0-50 \mathrm{~Hz}$. [8]; merubah frekuensi listrik dari catu daya PLN menjadi sesuai dengan kecepatan motor yang ingin diatur kecepatannya, dengan memanfaatkan Variabel Frequency Drive (VFD) dari inverter Altivar 12H075M2 berkapasitas 0,75 kW-1 HP, yaitu sistem mengendalikan kecepatan rotasi motor listrik arus bolak-balik (AC) [9]; menggunakan metode pengaturan kecepatan pengembangan kontrol vektor, yaitu metode Direct Torque Control (DTC). yang memungkinkan pengaturan fluks dan torsi secara langsung dan terpisah. Sistem dapat degunakan tanpa menggunakan sensor kecepatan. Proses pengaturan disulasikan dengan menggunakan aplikasi Matlab sehingga parameter yang digunakan dapat diujikan berulang untuk menghasilkan putaran kecepatan yang diinginkan [10].

Penelitian ini merancang sistem pengaturan tegangan motor induksi satu phasa tegangan arus bolak-balik meggunakan dimmer sebagai kontroler pulsa wide modulasi (PWM) yang terdiri dari rangkaian elektronik triac bi-directional. Kontroler PWM bekerja untuk yang memudahkan pengaturan arus sebagai regulator tegangan. Mesin pengering juga dipasangkan relay timer sebagai mengatur atau kontrol lamanya waktu pengeringan produk juga berfungsi sebagai peralatan proteksi dari arus pendek, sebagai antisipasi proteksi [11] terjadinya over speed pada pengeringan krupuk ditambahkan saklar normaly open dan normaly close.

\section{METODE PENELITIAN}

Studi penggunaan motor induksi satu phasa sebagai peniris minyak memperlihatkan hubungan antara tegangan, putaran terhadap waktu dan beban. Penggunaan dimmer dengan tegangan kerja 50-200 Volt, berkapasitas hingga 2000 Watt memungkinkan banyak variasi tegangan yang dapat dilakukan pengujian. Relay timer dengan setting kelipatan 30 detik digunakan sebagai kontrol waktu pengeringan alat. Besaran tegangan, putaran motor induksi diukur menggunakan tang amper dan tachometer, beban dan perubahannya yang simulasikan dengan kain bercairan diukur menggunakan neraca digital. Analisis 


\section{Jurnal TEKNO}

(Civil Engineeering, Elektrical Engineeering and Industrial Engineeering)

Vol. 16, No : 1, April 2019 , p-ISSN:1907-5243, e-ISSN: 2655-8416

performa mesin pengering dari penelitian dilakukan terhadap perubahan tegangan dan putaran; putaran terhadap beban dan setting waktu; serta penggunaan energi listrik dan torsi yang bekerja pada motor induksi.

Adapun spesifikasi dimmer, motor induksi yang dipergunakan sebagai berikut:

Tabel 1. Spesifikasi Dimmer dan Motor Induksi

\begin{tabular}{|c|c|c|c|c|}
\hline \multicolumn{3}{|c|}{ Dimmer } & \multicolumn{2}{|c|}{ Motor Induksi } \\
\hline Tegangan input & $:$ & $110-250 V_{A C}$ & Tegangan & $: \quad 200-240 \mathrm{~V}_{\mathrm{AC}}$ \\
\hline Tegangan output & : & $50-250 \mathrm{~V}_{\mathrm{AC}}$ & Frekuensi & $: \quad 50 \mathrm{~Hz}$ \\
\hline Maximum output & : & 2000 Watt & Putaran & $: \quad 480 / 1500 \mathrm{rpm}$ \\
\hline Arus output max. & : & 16 Ampere & Daya & : $\quad 0,3 \mathrm{HP}$ \\
\hline Range pengaturan & : & $50-250 \mathrm{~V}_{\mathrm{AC}}$ & Jumlah phasa & : Satu \\
\hline Tipe & : & $\begin{array}{l}\text { Triac } \\
\text { BTA16600B }\end{array}$ & Efisiensi & $40-80 \%$ \\
\hline
\end{tabular}

\subsection{Metode Penelitian}

Metode yang dipergunakan dalam penelitian ini adalah :

1. Metode eksperimental

Metode dengan pendekatan sistematis dan ilmiah untuk melakukan perubahan atau manipulasi suatu variabel tertentu dan pengukuran pada setiap perubahan dengan variabel lainnya

2. Metode dokumentasi

Metode ini adalah yang diperoleh dari buku, jurnal dan dokumen lainnya yang berkaitan dengan penelitian terdahulu dan data-data pendukung penelitian

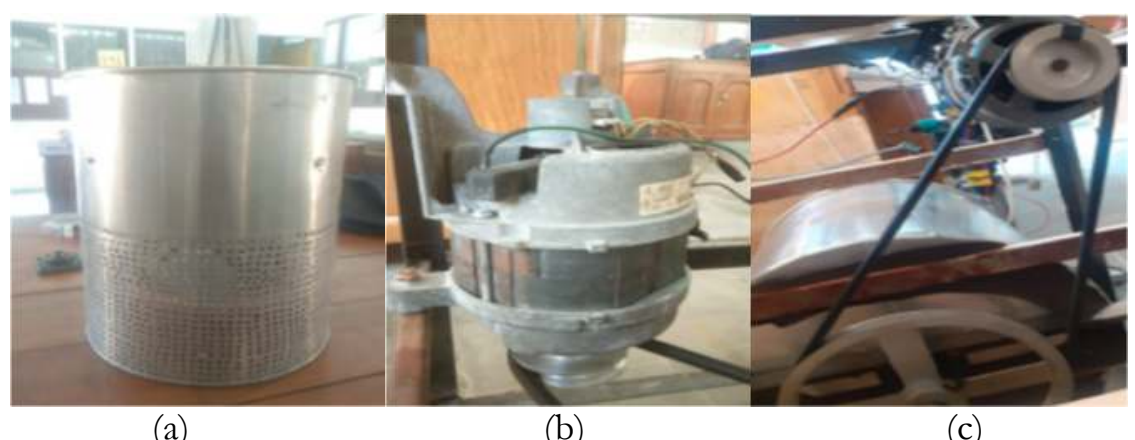

(a)

(b)

(c)

Gambar 1. Tabung peniris (a), Motor Listrik (b), Pully dan V-Belt (c)

\subsection{Langkah Penelitian}

Adapun langkah-langkah pembuatan mesin pengering adalah :

1. Persiapan alat dan bahan

2. Perakitan sistem mekanik, elektrik, sistem kontrol dan peralatam pendukung lainnya

3. Pengujian performance mesin pengering dengan variasi tegangan dan waktu 
4. Perhitungan perbandingan pulley,

$$
\frac{N_{2}}{N_{i}}=\frac{D_{1}}{D_{2}}
$$

5. Perhitungan torsi motor,

$$
\mathrm{T}=\frac{5252 \cdot P}{N}
$$

\subsection{Blok Diagram Penelitian}

Penelitian teridiri dari lima tahapan (Gambar 2). Tahapan pertaman dimulai dimulai dengan persiapan alat dan bahan pengering atau peniris minyak dengan motor induksi ini meliputi pembuatan layout alat, pembuatan rangka alat, penentuan dimensi tabung peniris atau filter (Gambar 1.a) yang terdiri dari diameter bawah, dan tingginya; dan bahan tabung luar pengering. Bahan tabung peniris terbuat dari bahan aluminium plat dengan ketebalan $3 \mathrm{~mm}$, di disain khusus karena harus terdapat lubang-lubang peniris, dan untuk tabung luar yang statis diameternya sedikit lebih besar untuk menambuk percikan minya tirisan dan dilengkapi dengan corong untuk mengeluarkan minyak hasil penirisan.

Selanjut dilakukan persiapan peralatan elektrik dan mekanik yang dipergunakan, yakni motor listrik (Gambar 1.b), dimmer, timer relay dan membuat pulley pembanding (Gambar 1.c) pada alat peniris dengan pulley motor listrik. Dilanjutkan dengan perakitan alat mekanik, mekanik dan sistem kontrol. Pengujian performa motor induksi dilakukan terhadap parameter waktu, tegangan, arus dan berat beban yang ditiriskan. konstan. Pengujian alat meliputi perubahan variabel tegangan, waktu; perhitungan torsi kerja; analisis performa mesin dalam bentuk grafik dan deskriptif, diakhiri dengan menarik kesimpulan sesuai dengan performa alat pengering dan torsi pada motor induksi

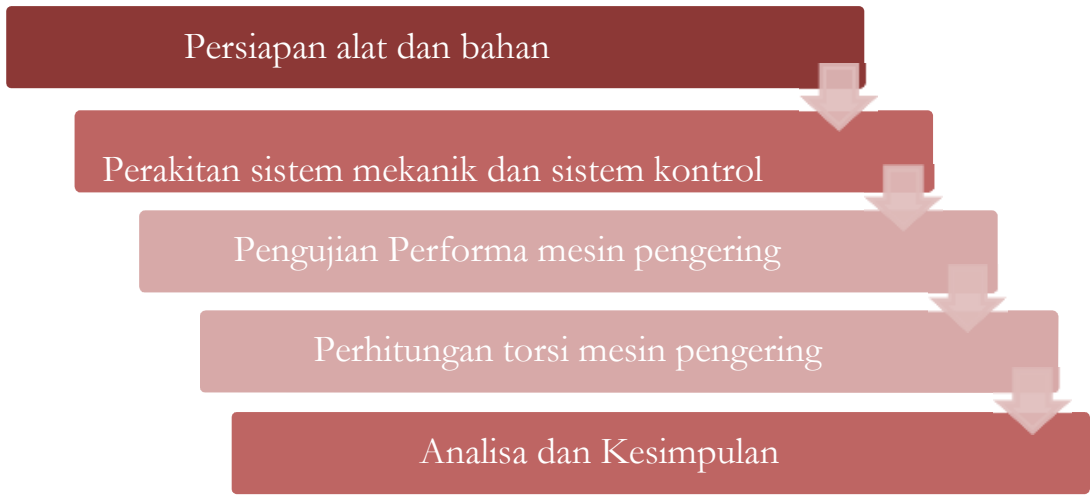

Gambar 2. Blok Diagram Penelitian

\section{Hasil dan Diskusi}




\section{Jurnal TEKNO}

(Civil Engineeering, Elektrical Engineeering and Industrial Engineeering)

Vol. 16, No : 1, April 2019 , p-ISSN:1907-5243, e-ISSN: 2655-8416

Mesin pengering bekerja berdasarkan putaran tabung filter (Gambar 1.a) dengan kecepatan untuk meminimalkan kadar minyak yang menempel pada makanan (Gambar 3). Minyak yang keluar dari tabung pengering akan tertahan pada lapisan terluar pengering yang statis dan akan mengalir menuju saluran pembuangan. Tabung bagian dalam digerakkan dengan penggerak utama adalah motor induksi melalui transmisi mekanik dua buah pulley dan V-belt. Motor induksi satu phasa dengan menggerakan pulley yang kecil menghasilkan putaran yang tinggi, dan sebagai penggerak mekanik pulley motor dihubungkan ke pulley pengering untuk mendapatkan rasio putaran yang diinginkan.

Timer atau pengatur waktu (Gambar 3) pada mesin pengering minyak pada pengujian dapat mengontrol waktu dalam rentang satuan detik hingga jam, dengan mengatur setting jarum penunjuk waktu yang diinginkan. Performa motor induksi dilakukan pengujian awal dengan setting waktu 30 detik untuk memperlihatkan pengaruh antara putaran motor dan tegangan yang diberikan. Setting selanjutnya dilakukan dengan tegangan lima step dimmer dilakukan pengujian mulai dengan tegangan 80 Volt, dengan penambahan 5 Volt hingga mencapai 100 Volt.

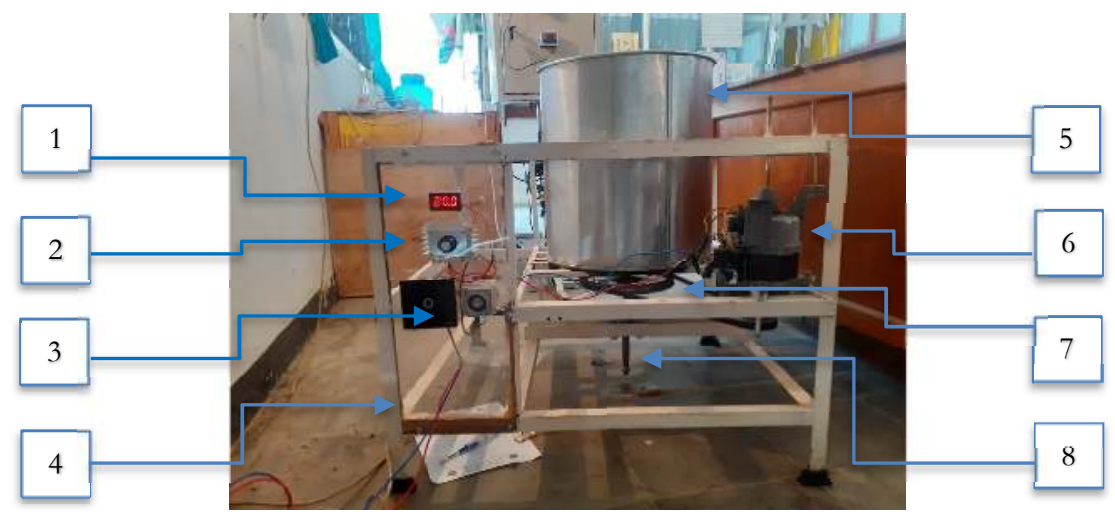

Gambar 2. Mesin Pengering

Keterangan gambar :
1. Display kecepatan motor
5. Tabung luar pengering
2. Dimmer
6. Motor Induksi
3. Timer
4. Rangka alat
7. Pulley
8. Poros pengering

Grafik hasil pengujian hubungan kecepatan putaran pengering dan tegangan (Gambar 3), secara umum memperlihatkan bahwa kenaikan tegangan mempengaruhi putaran motor. Pengurangan tegangan motor dengan mengatur dimmer mampu mempercepat putaran motor, dimana motor memiliki kecepatan putaran (rpm) lebih tinggi dari rating kerja motor yaitu 480/1500 rpm (Tabel 1). Namun ditegangan rendah 80-85 Volt putaran $(\mathrm{N})$ motor lebih rendah namun masih di dalam rating kecepatan motor induksi yaitu lebih kecil dari 1500 rpm. 
(Civil Engineeering, Elektrical Engineeering and Industrial Engineeering)

Vol. 18, No : 2, Oktober 2021, p-ISSN:1907-5243, e-ISSN: 2655-8416

Pengaturan putaran motor induksi relatif stabil dengan putaran $2500 \mathrm{rpm}$ pada tegangan 90-100 Volt atau step dimmer ke 3, 4 dan 5.

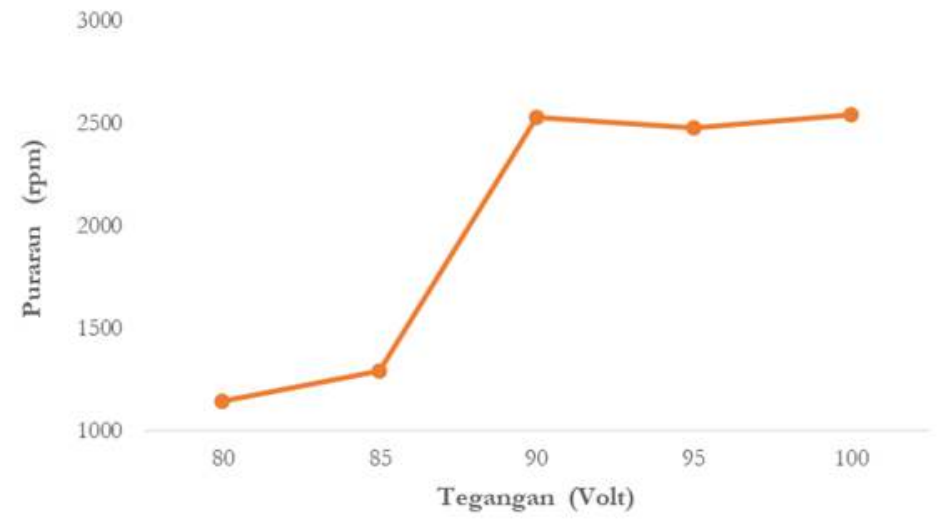

Gambar 3. Karakteris Tegangan dan Putaran Mesin Pengering

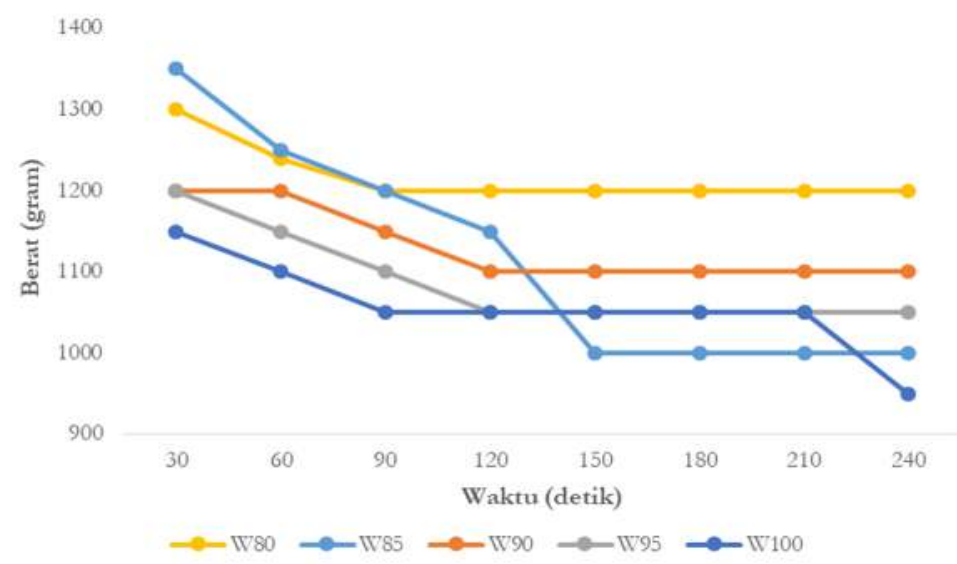

Gambar 4. Perubahan Berat terhadap Waktu Pengering

Untuk mendapatkan kemampuan pengeringan terhadap waktu, pengujian dilakukan dengan menggunakan memberikan beban (W). Pengujian ini menggunakan beban simulasi berupa kain basah dengan berat awal (Wo) 1700 gram. Perubahan berat benda silmulasi (Wn) diukur terhadap perubahan tegangan kerja yang dipergunakan dalam pengujian dan diakhir waktu yang setting timer.

Hasil pengujian perubahan kecepatan motor induksi dengan $\mathrm{n}$ waktu pada Gambar 4, menujukkan pada setting waktu 30-120 detik penurun berat 
maksimum, dan setelahnya berat benda relatif stabil hingga pengeringan dengan waktu maksimum 240 detik atau 4 menit. Besarnya tegangan yang diberikan pada motor mempengaruhi kecepatan penurunan berat, perubahan berat terkecil 950 gram didapatkan setelah 4 menit, dengan tegangan motor 100 Watt. Analisis terhadap tegangan awal dan waktu pengeringan, bahwa tegangan akan mempengaruhi kecepatan proses penirisan minyak; setting waktu 120 detik adalah setting waktu yang terbaik untuk mendapatkan beban minimum.

Kurangnya perawatan motor induksi ataupun kondisi motor yang sudah tua, dapat menyebabkan tahanan stator menjadi tidak seimbang. Hal ini akan mempengaruhi kinerja motor induksi pada torsi ( $\mathrm{T}$ ) atau putarannya. Pada motor induksi rotor belitan yang dipergunakan dalam rancangan mesin pengering/peniris, bertambahnya beban mengakibatkan semakin tidak seimbang tahanan statornya maka semakin besar torsi yang terjadi dan semakin kecil putaran yang dihasilkan. Berdasarkan persamaan pada sub (2.2) dan data motor (Tabel 1) diketahui daya motor adalah 0,3 Hp, dalam putaran $1143 \mathrm{rpm}$, besarnya torsi yang bekerja pada motor adalah,

$$
\begin{aligned}
& \mathrm{T}=\frac{5252 \times 0,3 \mathrm{Hp}}{1143 \mathrm{rpm}} \\
& \mathrm{T}=1,37 \mathrm{~N} . \mathrm{m}
\end{aligned}
$$

Berdasarkan persamaan ini dan pengujian mesin, dengan tegangan konstan berat benda dan waktu pengeringan mempengaruhi putaran dan torsi motor (Tabel 2). Pada T 30-120 detik hasil memperlihatkan torsi motor semakin kecil dengan berkurangnya bobot dan naiknya putaran motor pengering.

\begin{tabular}{|c|c|c|c|c|c|}
\hline $\begin{array}{c}\mathrm{T} \\
\text { (detik) }\end{array}$ & $\begin{array}{l}W_{0} \\
(\mathrm{gr})\end{array}$ & $\begin{array}{l}W_{80} \\
(\mathrm{gr})\end{array}$ & $\begin{array}{c}\mathrm{V}_{0} \\
\text { (Volt) }\end{array}$ & $\begin{array}{c}\mathrm{N}_{80} \\
(\mathrm{Rpm})\end{array}$ & $\begin{array}{c}\boldsymbol{\tau}_{80} \\
\text { (N.m) }\end{array}$ \\
\hline 30 & 1700 & 1300 & 80 & 1143 & 1,37 \\
\hline 60 & 1700 & 1240 & 80 & 1290 & 1,18 \\
\hline 90 & 1700 & 1200 & 80 & 1351 & 1,12 \\
\hline 120 & 1700 & 1200 & 80 & 1760 & 0,83 \\
\hline 150 & 1700 & 1200 & 80 & 2279 & 0,64 \\
\hline
\end{tabular}

Tabel 2. Hasil Pengujian dan Perhitungan Torsi Motor Mesin Pengering 


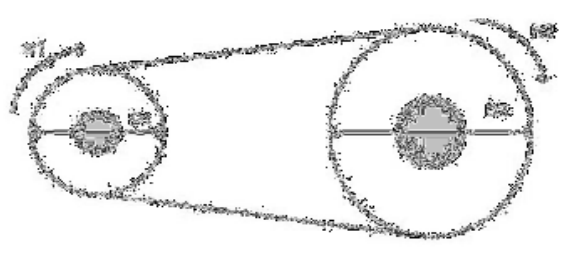

Gambar 5. Perbandingan Pulley

Putaran pada pulley motor pengering berbeda dengan putaran pada tabung peniris karena diameter pulley motor diperbesar untuk memperkecil putaran dari motor. Mengacu pada persamaan di point 2.2 maka dapat dihitung kecepatan putaran pulley pengering dengan asumsi diameter pully penggerak $\left(D_{1}\right)$, diameter pulley pengering $\left(\mathrm{D}_{2}\right)$, jumlah putaran pulley penggerak $\left(\mathrm{N}_{1}\right)$ jumlah putaran pulley pengering $\left(\mathrm{N}_{2}\right)$, dengan :

$$
\begin{aligned}
& \mathrm{D}_{1}=65 \mathrm{~mm} \\
& \mathrm{D}_{2}=240 \mathrm{~mm} \\
& \mathrm{~N}_{1}=1143 \mathrm{rpm}
\end{aligned}
$$

Maka,

$$
\begin{aligned}
& \mathrm{N}_{2}=\frac{1143 \times 65}{240} \\
& \mathrm{~N}_{2}=\frac{74295}{240} \\
& \mathrm{~N}_{2}=309 \mathrm{rpm}
\end{aligned}
$$

Hasil perhitungan dengan persamaan yang sama dengan putaran dan waktu berbeda terlihat pada Tabel 3. Diameter puley pengering yang lebih kecil mengurangi kecepatan berbading lurus dengan kecepatan. Bila menginginkan kecepatan pengeringan yang lebih rendah maka cukup dengan memperbesar pully pengering dan menggantinya dengan panjang V-belt yang lebih panjang pula. Pengeringan kecepatan rendah dapat dipalikasikan pada pengeringan makan bertesktur lembut, idak padat dan mudah rusak akibat perubahan kecepatan.

Tabel 3. Hasil Kecepatan Putaran Pulley Mesin Pengering

\begin{tabular}{cccc}
\hline $\mathbf{T}$ & $\mathbf{\tau}_{\mathbf{8 0}}$ & $\mathbf{N}_{\mathbf{1}}$ & $\mathbf{N}_{\mathbf{2}}$ \\
(detik) & $\mathbf{( N . m )}$ & $\mathbf{( R \mathbf { p m } )}$ & $\mathbf{( R \mathbf { p m } )}$ \\
\hline 30 & 1,37 & 1143 & 309 \\
60 & 1,18 & 1290 & 349 \\
90 & 1,12 & 1351 & 365 \\
120 & 0,83 & 1760 & 476 \\
150 & 0,64 & 2279 & 617 \\
\hline
\end{tabular}




\section{KESIMPULAN}

Performa motor induksi sebagai mesin pengering stabil dengan putaran 2500 rpm pada tegangan 90-100 Volt atau step dimmer ke 3, 4 dan 5 dengan waktu pengeringan 90-120 detik. Penurunan beban dalam proses pengeringan menaikkan putaran, sebaliknya torsi motor akan semakin kecil dengan bertambahnya putaran motor dan lama proses pengeringan. Penambahan diameter pulley pengeringan akan mengurangi kecepatan putaran motor.

\section{REFERENCES}

[1] S. J. Chapman, Electrical Machinery Fundamental 5th Edition, vol. 53, no. 9. 2012.

[2] M. Soleimani, M. N. Alizadeh, and M. Moallem, "Economical replacement decision for induction motors in industry," in 2018 IEEE Texas Power and Energy Conference, TPEC 2018, 2018, vol. 2018-Febru, pp. 1-6, doi: 10.1109/TPEC.2018.8312086.

[3] Z. Anthony and E. Erhaneli, "Desain Lilitan Motor Induksi 1-Fasa dengan 4 Kumparan yang Tidak Identik Sama," EECCIS, vol. 12, no. 2, pp. 89-92, 2018.

[4] M. Naim, "Pengaruh Modifikasi Belitan Stator Motor Induksi Satu Phasa Starting Kapasitor Pada Mesin Bor Meja Terhadap Arus dan Daya listrik serta Putaran Motor," VERTEX ELEKTRO, vol. 12, no. 2, pp. 34-43, 2020, doi: 10.26618/jte.v12i2.4228.

[5] G. Prasidya, R. Sitepu, and W. Andyardja, "Mesin Peniris Tiga Jenis Kripik Berbasis Motor Listrik Tiga Fasa dan Mikrokontroler Arduino Uno," Ampere, vol. 4, no. 2, pp. 288-296, 2019.

[6] S. Wasisto, I. L. I. Purnama, and P. W. Anggoro, "Perancangan Mesin Peniris Untuk Aneka Makanan Ringan Hasil Gorengan," Proceeding SENDI_U, vol. 2016, pp. 347-355, 2016.

[7] H. F. Felayati et al., "Uji Performansi Mesin ' Spinner Pulling Oil' Sebagai Pengentas Minyak Otomatis Dalam Peningkatan Produktifitas Abon Ikan Patin (Pangasius pangasius)," J. Keteknikan Pertan. Trop. dan Biosist., vol. 4, no. 1, pp. 41-47, 2016.

[8] N. Evalina and A. A. Zulfikar, "Pengaturan Kecepatan Putaran Motor Induksi 3 Fasa Menggunakan Programmable Logic Controller," J. Electr. Technol., vol. 3, no. 2, pp. 73-80, 2018.

[9] E. S. Nasution and A. Hasibuan, "Pengaturan Kecepatan Motor Induksi 3 Phasa Dengan Merubah Frekuensi Menggunakan Inverter ALTIVAR 12P," Sist. Inf. ISSN, vol. 2, no. 1, pp. 25-34, 2018.

[10] U. Khasanah, S. Supari, and S. Heranurweni, "SIMULASI PENGATURAN KECEPATAN MOTOR INDUKSI 3 PHASA DENGAN DIRECT TORQUE CONTROL MENGGUNAKAN MATLAB," eLEKTRIKA, vol. 9, no. 1, p. 13, 2018, doi: 
(Civil Engineeering, Elektrical Engineeering and Industrial Engineeering)

Vol. 18, No : 2, Oktober 2021 , p-ISSN:1907-5243, e-ISSN: 2655-8416

10.26623/elektrika.v9i1.1109.

[11] D. Darmawansyah, M. K. A. Rosa, and I. N. Anggraini, "Sistem Proteksi Motor Induksi 3 Fasa Terhadap Bermacam Gangguan Menggunakan Mikrokontroller," J. Amplif. J. Ilm. Bid. Tek. Elektro Dan Komput., vol. 10, no. 1, pp. 9-17, 2020, doi: 10.33369/jamplifier.v10i1.15168. 